\title{
Lifestyle Modification Strategy for Patients with Premature Ejaculation as Metabolic Syndrome
}

\author{
Yu Seob Shin ${ }^{1}$ (iD, Hong Seok Shin ${ }^{2}$ (iD), Jong Kwan Park ${ }^{1}$ (iD \\ ${ }^{1}$ Department of Urology, Chonbuk National University Medical School, Research Institute of Clinical Medicine of Chonbuk National \\ University-Biomedical Research Institute and Clinical Trial Center of Medical Device of Chonbuk National University Hospital, Jeonju, \\ ${ }^{2}$ Department of Urology, Catholic University of Daegu School of Medicine, Daegu, Korea
}

This is an Open Access article distributed under the terms of the Creative Commons Attribution Non-Commercial License (http://creativecommons.org/licenses/by-nc/4.0) which permits unrestricted non-commercial use, distribution, and reproduction in any medium, provided the original work is properly cited.

Premature ejaculation (PE) is the most commonly reported form of sexual dysfunction in men, with a prevalence varying from $19 \%$ to about $30 \%$ in the male population [1]. PE refers to an inability to delay ejaculation or having less perceived control over ejaculation, based on the guidelines for PE of the International Society for Sexual Medicine published in 2014 [2]. To some extent, the quality of life (QOL) for patients and their partners, including the sexual satisfaction of both partners, sexual confidence, and interpersonal relationships, are influenced by PE.

The metabolic syndrome (MetS) is a common metabolic disorder that results from changing life style and increasing obesity [3]. Various metabolic factors involve in development of cardiovascular disease, such as glucose intolerance, insulin resistance, central obesity, dyslipidemia, and hypertension [3]. Although there are a few studies available about the relationship between MetS and QOL, a growing body of evidence has shown significant association between MetS and the worsening of QOL [4].

I have carefully read the article published in The
World Journal of Men's Heath by Jeh et al [5], and his findings and conclusions are indeed interesting. This article is one of the few reports which addresses the issue of PE and MetS. In their study, of 1,029 men, 74 subjects (7.2\%) had acquired PE and 111 (10.8\%) had MetS. Multivariate analysis showed that the presence of MetS (odds tatio=2.20, $\mathrm{p}=0.022$ ) were significantly correlated with the prevalence of acquired PE [5]. The underlying mechanism by which MetS contributes to the occurrence of PE has not been elucidated, but there are some hypotheses. First, MetS may induce psychological changes such as depression, which may precipitate or maintain PE. Second, MetS can influence the etiology of PE by inducing changes in serotonergic receptor function, which is the primary organic cause of PE. Third, MetS induced tissue inflammation such as prostatitis may contribute to the occurrence of PE. However, there are some points to be explained in the study. First, PE was diagnosed by self-reported questionnaire for ejaculatory latency. Self-reported data may be quite different from stopwatch-measured ejaculatory latency. Second, in addition to medical and

Received: Jan 19, 2019 Revised: Apr 9, 2019 Accepted: May 26, 2019 Published online Jul 3, 2019

Correspondence to: Hong Seok Shin (iD https://orcid.org/0000-0002-5697-2744

Department of Urology, Catholic University of Daegu School of Medicine, 33 Duryugongwon-ro 17-gil, Nam-gu, Daegu 42472 , Korea.

Tel: +82-53-650-4673, Fax: +82-53-626-5301, E-mail: uroshin@cu.ac.kr 


\section{MEN's HEALTH}

psychological factors, interpersonal factors can be a major cause of $\mathrm{PE}$, and there is a statistically significant difference in marital status between $\mathrm{PE}$ and non PE groups. Therefore, a well designed study with standardized protocols to evaluate relationship of MetS and $\mathrm{PE}$ is needed to verify these findings. Even with these limitations we believe that their finding is meaningful in that they comprehensively analyzed various factors that are known to play a part in the onset of PE.

Lifestyle modification strategies are foremost in the treatment and prevention of MetS. There is complete agreement that weight loss is associated with significant improvements in the clinical abnormalities of MetS. In our opinion, similar to the role of lifestyle modification in the management of MetS, there may be a role for lifestyle modification to prevent progression or even enhance the regression in the earliest manifestations of PE.

\section{Conflicts of Interest}

The authors have no potential conflicts of interest to disclose.

\section{Author Contribution}

Conceptualization: YSS, HSS, JKP. Writing-original draft:
Yu Seob Shin, et al: Lifestyle Modification for PE as MetS

YSS, HSS. Writing-review \& editing: YSS, HSS, JKP.

\section{REFERENCES}

1. Bai Y, Pu C, Han P, Li J, Yuan H, Tang Y, et al. Selective serotonin reuptake inhibitors plus phosphodiesterase-5 inhibitors for premature ejaculation: a systematic review and metaanalysis. Urology 2015;86:758-64.

2. Althof SE, McMahon CG, Waldinger MD, Serefoglu EC, Shindel AW, Adaikan PG, et al. An update of the International Society of Sexual Medicine's guidelines for the diagnosis and treatment of premature ejaculation (PE). J Sex Med 2014;11: 1392-422.

3. Ansarimoghaddam A, Adineh HA, Zareban I, Iranpour S, HosseinZadeh A, Kh F. Prevalence of metabolic syndrome in Middle-East countries: meta-analysis of cross-sectional studies. Diabetes Metab Syndr 2018;12:195-201.

4. Lee YJ, Woo SY, Ahn JH, Cho S, Kim SR. Health-related quality of life in adults with metabolic syndrome: the Korea National Health and Nutrition Examination Survey, 2007-2008. Ann Nutr Metab 2012;61:275-80.

5. Jeh SU, Yoon S, Choi JH, Do J, Seo DH, Lee SW, et al. Metabolic syndrome is an independent risk factor for acquired premature ejaculation. World J Mens Health 2019;37:226-33. 